
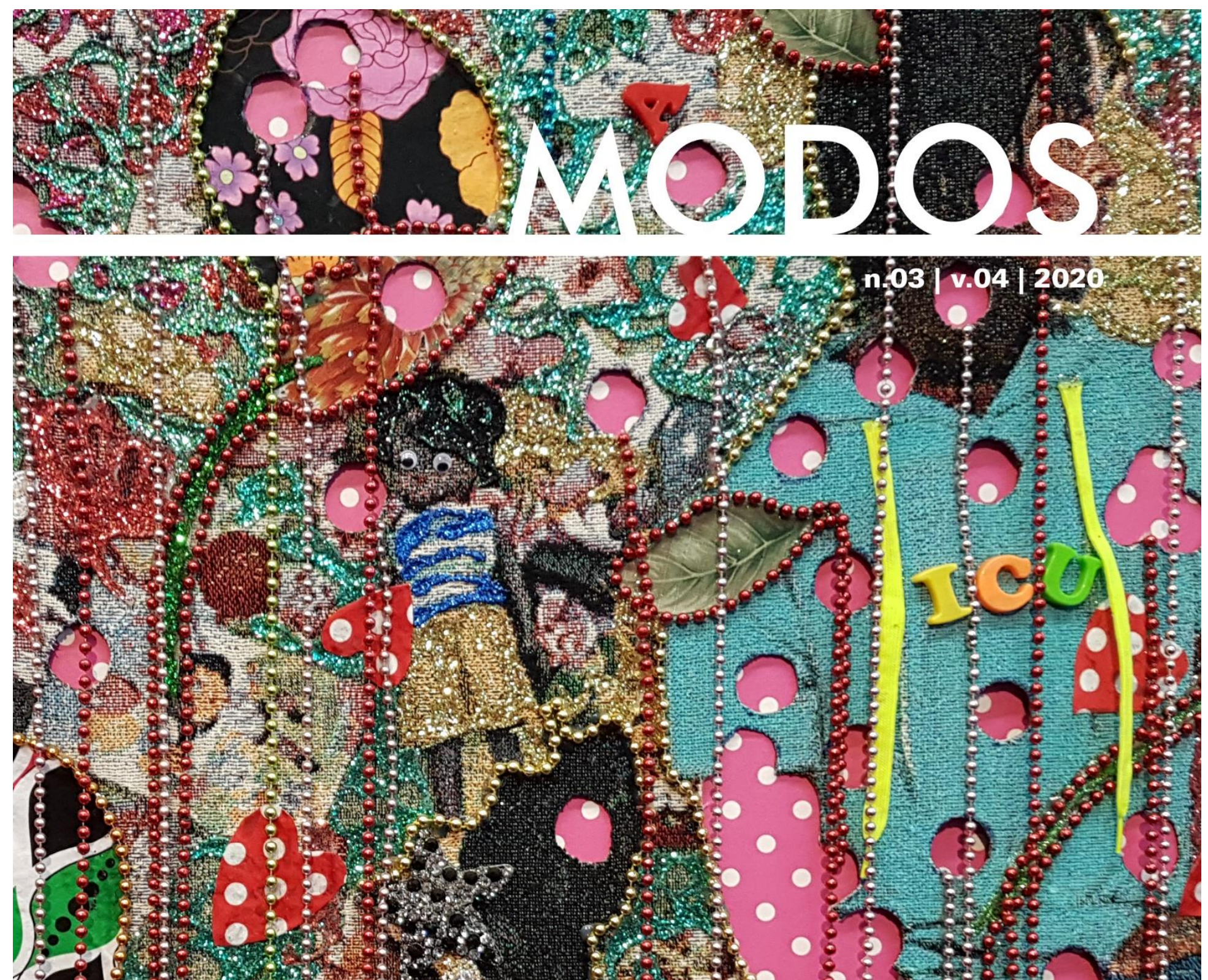

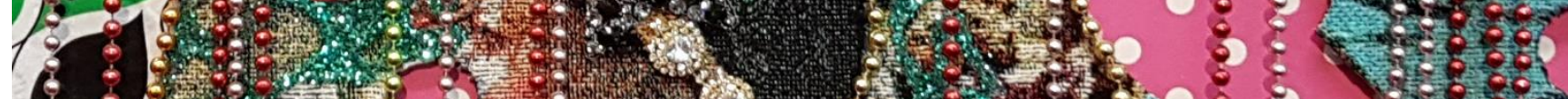

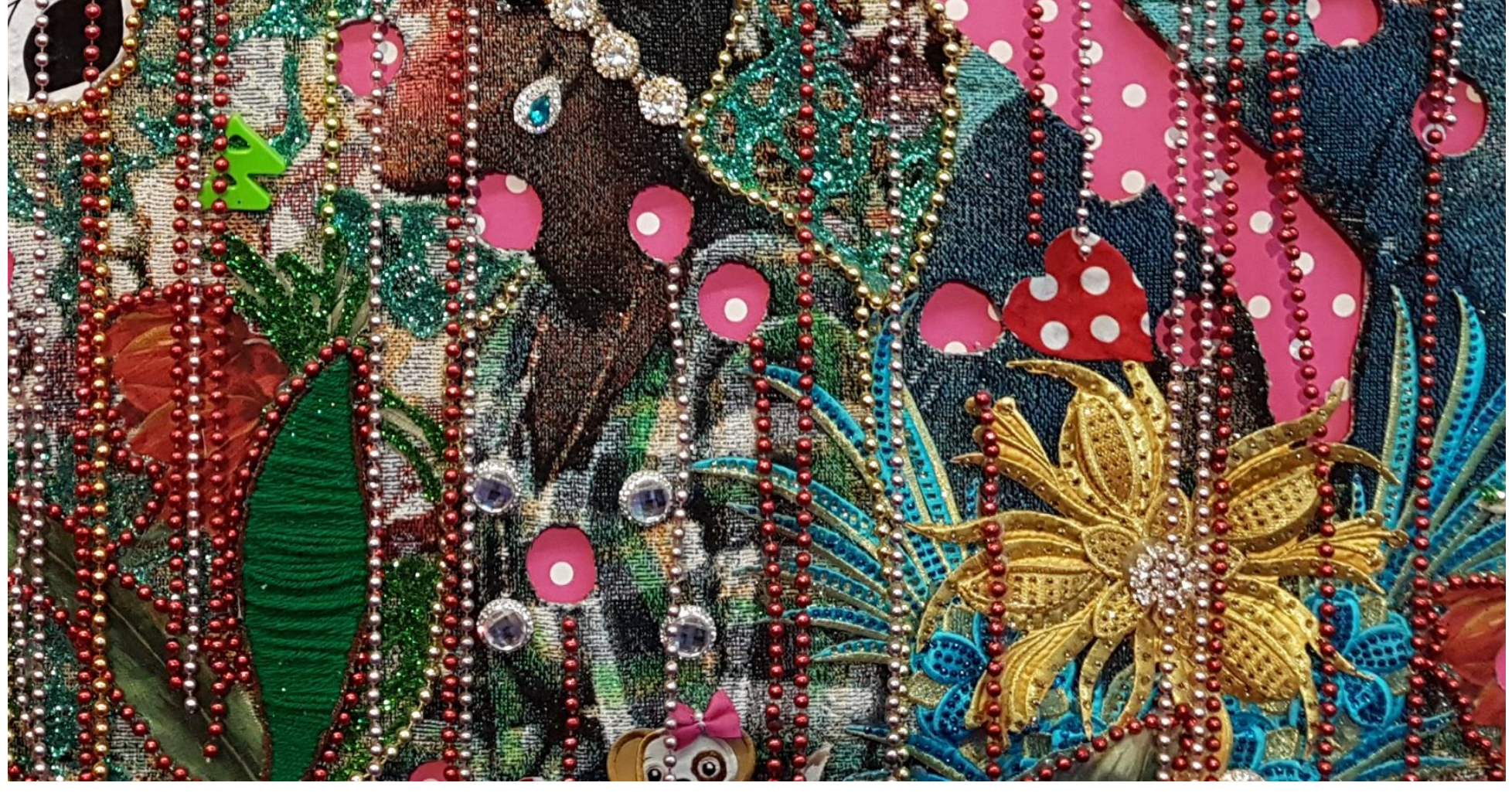




\section{MODOS. REVISTA DE HISTÓRIA DA ARTE}

Grupo de Pesquisa MODOS - História da Arte: modos de ver, exibir e compreender

Programa de Pós-graduação em Artes Visuais da Universidade Estadual de Campinas

Programa de Pós-graduação em Artes Visuais da Universidade Federal do Rio de Janeiro

Programa de Pós-graduação de Artes Visuais da Universidade de Brasília

Programa de Pós-graduação em Artes Visuais da Universidade Federal do Rio Grande do Sul

Programa de Pós-graduação em Artes Visuais da Universidade Federal da Bahia

Programa de Pós-graduação em Artes da Universidade do Estado do Rio de Janeiro

\section{UNIVERSIDADE ESTADUAL DE CAMPINAS \\ University of Campinas}

Dr. Marcelo Knobel

Reitor

Dr. Paulo Adriano Ronqui

Diretor do Instituto de Artes

Dra. Maria de Fátima Morethy Couto

Coord. do PPG em Artes Visuais

UNIVERSIDADE DE BRASÍLIA

University of Brasilia

Dra. Márcia Abrahão Moura

Reitora

Dra. Fátima Aparecida dos Santos

Diretora do Instituto de Artes

Dr. Emerson Dionisio Gomes de Oliveira Coord.do PPG em Artes Visuais

UNIVERSIDADE FEDERAL DA BAHIA

Federal University of Bahia

Dr. João Carlos Salles Pires da Silva

Reitor

Dra. Nanci Santos Novais

Diretora da Escola de Belas Artes

Dr.Edgard Mesquita de Oliva Junior

Coord.do PPG em Artes Visuais
UNIVERSIDADE FEDERAL DO RIO DE JANEIRO

Federal University of Rio de Janeiro

Dra. Denise Pires de Carvalho

Reitora

Dra. Madalena Grimaldi

Diretora da Escola de Belas Artes

Dr. Carlos Azambuja Rodrigues

Coord.do PPG em Artes Visuais

UNIVERSIDADE FEDERAL DO RIO GRANDE DO SUL

Federal University of Rio Grande do Sul

Dr. Rui Vicente Oppermann

Reitor

Dr. Raimundo José Barros Cruz

Diretor do Instituto de Artes

Dr. Paulo Antônio de Menezes Pereira da Silveira

Coord. do PPG em Artes Visuais

UNIVERSIDADE DO ESTADO DO RIO DE JANEIRO

State University of Rio de Janeiro

Dr. Ricardo Lodi Ribeiro

Reitor

Dr. Alexandre Sá Barretto da Paixão

Diretor do Instituto de Artes

Dra. Sheila Cabo Geraldo

Coord.do PPG em Artes 
EQUIPE EDITORIAL/ GRUPO DE PESQUISA

MODOS - História da Arte: modos de ver, exibir e compreender

Dra. Ana Maria Albani de Carvalho

Federal University of Rio Grande do Sul

Dra. Ana Maria Tavares Cavalcanti

Federal University of Rio de Janeiro

Dr. Emerson Dionisio Gomes de Oliveira

University of Brasilia

Dr. Luiz Alberto Freire

Federal University of Bahia

Dr. Luiz Cláudio da Costa

State University of Rio de Janeiro

Dra. Maria de Fátima Morethy Couto

University of Campinas

Dra. Marize Malta

Federal University of Rio de Janeiro

\section{CONSELHO CIENTÍFICO}

Dra. Anne Benichou

Université du Québec à Montréal

Dr. Bernard Guelton

Université Paris 1

Dra. Catherine Dossin

Purdue University

Dr. Jean-Marc Poinsot

Université Rennes 2

Dr. Jesus Pedro Lorente Lorente

Universidad de Zaragoza

Dr. José Emilio Burucúa

Universidad de Buenos Aires

Dr. Jorge Coli

University of Campinas

Dr. Márcio Seligmann-Silva

University of Campinas

\section{Dr. Paulo Knauss}

Fluminense Federal University

Dra. Raquel Henriques da Silva

New University of Lisbon

Dra. Sonia Gomes Pereirea

Federal University of Rio de Janeiro

Dra. Sônia Salzstein

University of São Paulo

Dr. Stéphane Huchet

Federal Universtity of Minas Gerais

EDITOR-CHEFE

Dra. Maria de Fátima Morethy Couto

University of Campinas

EDITORES-ASSISTENTES

Dr. Emerson Dionisio Gomes de Oliveira

University of Brasilia

Dra. Marize Malta

Federal University of Rio de Janeiro

PROJETO GRÁFICO/ EDITORAÇÃO ELETRONICA

Dra. Marize Malta

Federal University of Rio de Janeiro

Ivan Avelar

University of Campinas

CAPA

Ms. Pedro Ernesto Freitas Lima

University of Brasilia

\section{CAPA}

...love... (when they grow up...), 2016, de Ebony G.

Patterson, (detalhe). 32a Bienal de São Paulo, 2016.

Foto: E.D. Oliveira.

Dados Internacionais de Catalogação na Publicação (CIP)

MODOS. Revista de História da Arte: publicação eletrônica do Programa de Pós-graduação em Artes Visuais da Universidade Estadual de Campinas. - v.4, n.3 (2020) - Campinas: PPGAVUnicamp, set.2020.

Quadrimestral

Resumo em português e inglês.

Disponivel no SEER: http://www.publionline.iar.unicamp.br/index.php/mod/index

ISSN: 2526-2963

1. História da Arte. 2. Artes Visuais. 3. Teoria da Arte. 4. Crítica de Arte 5. Museologia

CDU: 7(091)

\footnotetext{
MODOS. REVISTA DE HISTÓRIA DA ARTE

Programa de Pós-Graduação em Artes Visuais - Instituto de Artes - Universidade Estadual de Campinas

Rua Elis Regina,50. Cidade Universitária "Zeferino Vaz". Barão Geraldo, Campinas-SP - CEP 13083-854 e-mail: revista.modos@gmail.com

Todos os artigos assinados são de inteira responsabilidade de seus autores, não cabendo qualquer responsabilidade legal sobre seu conteúdo à revista.
} 


\section{EDITORIAL}

\section{ARTIGOS}

Jaime Fernandes Simões compondo narrativas sobre a art brut em Portugal

Jaime Fernandes Simões, framing narratives about art brut in Portugal

Stefanie Gil Franco

Ecos del Atlántico Sur sobre suelo británico: el monumento a San Martin en Londres y la exposición Art from Argentina 1920-1994

Echoes of the South Atlantic on British soil: the monument of San Martin in London and the exhibition "Art from Argentina: 1920-1994"

Agustin Diez Fischer

O que pode a arte contemporânea no museu: uma reflexão sobre contemplação suspensa, de Rubens Mano

What can contemporary art do in a museum: a reflection on contemplação suspensa, by Rubens Mano

Fernanda Carvalho de Albuquerque

\section{DOSSIÊ}

0 retorno a Aby Warburg no discurso historiográfico artístico contemporâneo

The return to Aby Warburg in the current discourse of Art History

\section{Apresentação/Presentation \\ Vera Pugliese; Roberto Casazza}

Reinventar a primavera, ou as filiações da revolta

Reinvent the spring, or the affiliations of the revolt

Georges Didi-Huberman; Vera Pugliese (trad.)

Warburg e Burckhardt

Warburg and Burckhardt

Cássio da Silva Fernandes

Aby Warburg y el ritual de las imágenes

Aby Warburg and the Ritual of Images

Hernán UIm

Actualizaciones historiográficas, redes de scholars. De la Historia de la Magia de Warburg/Yates a la del Esoterismo occidental de Faivre/Hanegraaff

Historiographical updates, networks of scholars. From the History of Magic of Warburg / Yates to History of Western Esotericism of Faivre/Hanegraaff

Juan Pablo Bubello

Prancha 25 do Atlas Mnemosyne e Agostino di Duccio: Apolíneo e Dionisíaco no Oratório de São Bernardino em Perugia

Panel 25 of Atlas Mnemosyne and Agostino di Duccio: Apollonian and Dionysian at San Bernardino's Oratory at Perugia

Luana Maribele Wedekin; Sandra Makowiecky

Transmisión y diálogo como Nachleben. Raymond Klibansky: un filósofo en el círculo de la Biblioteca Warburg

Transmission and dialogue as Nachleben. Raymond Klibansky: A Philosopher in The Warburg Library Network Philippe Despoix; Jillian Tomm; Ramón de Elía (trad.) 
Suite française. Georges Didi-Huberman, uma experiência na História da arte French Suite. Georges Didi-Huberman, an experiment in History of art

Stéphane Huchet

Warburg, Agamben, Deleuze: a imagem e a filosofia da diferença

Warburg, Agamben, Deleuze: the image and the philosophy of difference

Mateus Carvalho Nunes

A Ninfa como personagem teórica de Aby Warburg

The Nymph as a theoretical character of Aby Warburg

Daniela Queiroz Campos

De tauroctonías y estrellas: Mitra y la vida de una imagen

On tauroctonies and stars: Mithras and the life of an image

Alejandro Gangui

Em louvor das impurezas na historiografia da arte: Ernesto de Sousa e o estudo da escultura portuguesa

In praise of impurities in the historiography of art: Ernesto de Sousa and the study of Portuguese sculpture

Maria Manuela Restivo

Le déjeuner sur l'herbe e a ciência da cultura dedicada à história da arte, de Aby Warburg

Le déjeuner sur l'herbe and the science of culture dedicated to the history of art, by Aby Warburg

Luís Edegar Costa

Manet, Manebit! 0 "Manet e a Antiguidade italiana" de Aby Warburg como autorretrato psicointelectual

Manet, Manebit! Aby Warburg's "Manet and Italian Antiquity" as psycho-intellectual self-portrait

Uwe Fleckner; Vera Pugliese e Victor Zaiden (trads.)

Personificaciones artísticas y práctica historiográfica. El caso de Johannes Sambucus (1531-1584)

Artistic Personifications and Historiographical Practice. The Case of Johannes Sambucus (1531-1584)

Silvina Vidal

Mnemosyne, ou a cinematografia sem aparelho

Mnemosyne, or the cinematography without apparatus

Philippe-Alain Michaud; Vera Pugliese (trad.)

Sobre o selo de Aby Warburg: fronteiras, trânsitos e retornos

On the stamp of Aby Warburg: frontiers, transits and returns

Vera Pugliese

The Epistemic Advantage of Self-Analysis for Cultural-Historical Insights: The variants of Warburg's manuscripts of Indians Journey

A vantagem epistêmica da autoanálise para insights histórico-culturais: as variantes dos manuscritos de Warburg em sua jornada indigena

Sigrid Weigel 


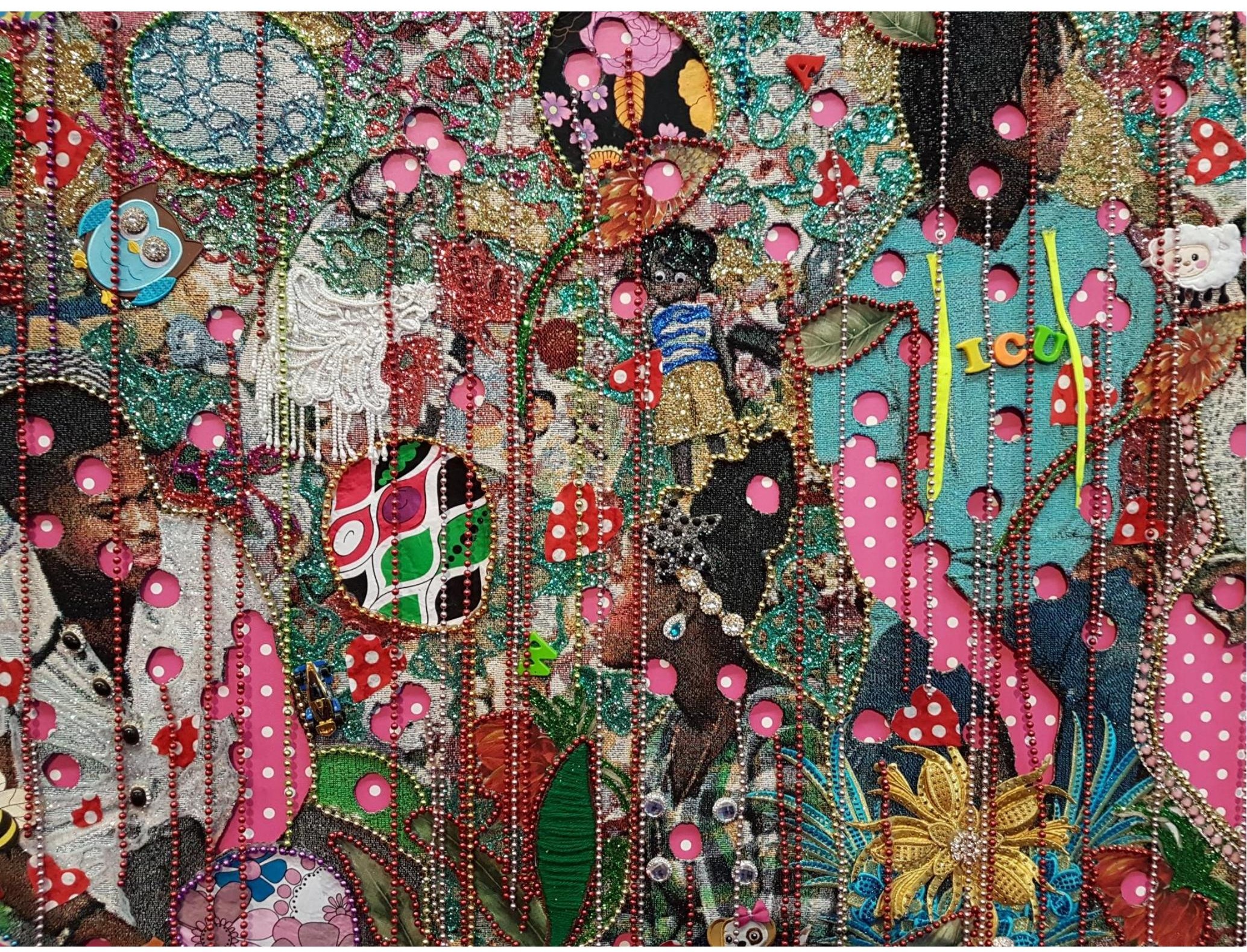

Ressurgências e sobrevivências das ideias de Warburg Resurgences and survivals of Warburg's ideas

\section{Emerson Dionisio Oliveira; Maria de Fátima Morethy Couto; Marize Malta Editores}

Como citar:

OLIVEIRA, E.D.; COUTO, M.F.M.; MALTA, M. Ressurgências de Warburg e sobrevivências na arte. MODOS. Revista de História da Arte. Campinas, v. 4, n.3, p.05-14, set. 2020. Disponivel em: <https://www.publionline.iar.unicamp.br/index.php/mod/article/ view/4611>; DOI: https://doi.org/10.24978/MOD.V4l3.4672.

Imagem: ...love... (when they grow up...), 2016, de Ebony G. Patterson, (detalhe). $32^{\mathrm{a}}$ Bienal de São Paulo, 2016. Foto: E.D. Oliveira. 
"O problema está no meio" escreve Aby Warbug em 1918 (2013). O historiador alemão é o eixo que atravessa a $12^{\mathrm{a}}$ edição da MODOS. Direta ou indiretamente, o escopo desta revista deve muito a Warburg, pois MODOS é uma revista que dedica especial atenção "ao meio", percebendo-o como 0 amplo campo de circulação que organiza as maneiras de interpretar e conhecer arte. Maneiras que oganizam, reorganizam e desorganizam os processos de colecionamento, os regimes expositivos, os discursos críticos, as narrativas curatoriais e historiográficas. Ou seja, um modo de perceber a plasticidade dos sentidos suscitados e operados para e pela produção artística. Somos todos devedores de Warbug por sua capacidade de introduzir a obra de arte numa rede de imagens que nos orienta a pensá-la como parte da cultura visual mais ampla, além de inscrevê-la na memória cultural não linear, nem literal. Seus estudos combatem as teorias que desvinculam a intepretação dos fenômenos culturais da produção artística, aproximando historiadores da arte de teorias da imagem, do cinema, da semiótica, da literatura, da comunicação, da antropologia, entre outras áreas do conhecimento, esgarçando as froneiras disciplinares.

Sabemos cada vez mais sobre Warburg, mas o reconhecimento deste estudioso do Renascimento italiano e do norte da Europa, além da Antiguidade, foi tardio, especialmente na América do Sul. Alguns dos autores que contribuem nesta edição preocupam-se com a ausência de traduções dos textos de Warbug e, sobretudo, com a construção de uma fortuna crítica que tenta nos orientar frente a um material fragmentado e disperso em cartas, esboços, cursos, textos acadêmicos e conferências.

Neste tocante, revistas científicas brasileiras têm sido fundamentais na acolhida de artigos sobre 0 pensamento warbuguiano. É preciso destacar a iniciativa da Arte e Ensaios (EBA/UFRJ), que em 2009, sob um dossiê organizado por Cezar Bartholomeu, traduziu, da versão italiana, a introdução de Warburg para o Atlas Mnemosyne, além do texto de Giorgio Agamben de 1975, "Aby Warburg e a ciência sem nome"1. Na ocasião, ao se referir à "espirial hermenêutica" delineada pelo filósofo italiano para o pensamento de Warburg, o organizador apontava o fascínio produzido sobre 0 pensamento contemporâneo e sua produção:

É de interesse pensar que a figura dessa espiral, que indica ao mesmo tempo
descentramento e aprofundamento histórico agenciado pela obra de arte, refere tais
características ao problema do arquivo na arte contemporânea: mais que imagens
produzidas conforme um dispositivo conceitual, as imagens do atlas são o próprio
desvirtuamento de qualquer dispositivo conceitual, exigindo, em suas articulações
caracterizadas por essa patologia simbólica que se renova, questionar sua própria
posição (qualquer posição de sujeito) no sistema que produz a arte (Bartholomeu,
2009: 118).

Em 2017, foi a vez da Figura: Studies on the Classical Tradition (volume 5) publicar o dossiê "Aby Warburg e sua tradição", resultado de Colóquio Internacional realizado em São Paulo, no mesmo ano. Figura publicou textos especialmente dedicados ao estudo da tradição historiográfica e interpretação de Warburg, em contextos histórico-artísticos diversos, de autores como Patricia Meneses, Maurizio Ghelardi, Norval Baitello Junior, Leão Serva, José Geraldo Costa Grilo, José Burucúa, Nicolás Kwiatkowski, Naiara Damas, Renato Ferreira Lopes, Serzenando Vieira Neto, Rhuan Fernandes Gomes, lanick Takaes e Cássio Fernandes, este último também presente nesta edição da MODOS.

Antes dessas iniciativas, importantes periódicos investiram na difusão do pensamento warburguiano e suas intepretações. História: Questões \& Debates publicou "Aby Warburg entre a arte florentina do retrato e um retrato de Florença na época de Lorenzo de Medici" (Fernandes 2004). ArtCultura publicou "O lugar da imagem na reinstalação warburguiana" (Lehmkuhl, 2005). Locus-Revista de 
História lançou "Jacob Burckhardt e Aby Warburg: da arte à civilização italiana do Renascimento" (Fernandes, 2006). Sociedade e Estado publicou "Sobre el método de la interpretación documental y el uso de las imágenes en la sociología: Karl Mannheim, Aby Warburg y Pierre Bourdieu" (Barboza Martínez, 2006) e Concinnitas "Arquivos da Memória: Aby Warburg a História da Arte e a Arte Contemporânea" (Mattos, 2007). Esta última revista publicou, ainda, textos de dois importantes intérpretes de Warburg na América do Sul. O pioneiro José Emilio Burucúa (2012) com "Repercussões de Aby Warburg na América Latina", com tradução de Alberto Chillón, onde podemos ler: "Em linhas gerais, o conhecimento da obra e da teoria da cultura construída por Aby Warburg tem sido, na América Latina, tão tardio quanto no resto do mundo. (...)Tal tem sido a base textual de um interesse sempre crescente no México e na América do Sul, a ponto de se converter numa espécie de moda intelectual, de mania acadêmica pela obra de Aby Warburg durante a última década" (2012: 252). E "Aby Warburg: a astrologia como instrumento de orientação do homem no cosmos" de Cássio Fernandes (2019a). Importante referência no assunto, como se poderá constatar nesta edição², Fernandes (2019c) foi publicado por Visualidades no mesmo ano, com artigo intitulado "Aby "Warburg: intercâmbios culturais entre o Norte e o Sul".

Em 2010, a Revista de Filosofia: Aurora acolheu o texto de Ignacui Martínez, "El Arte como manipulación en Aby Warburg". Naquele mesmo ano, História da Historiografia publicou "Aby Warburg e a pós-vida das Pathosformeln antigas" de Felipe Charbel Teixeira (2010) e "O Quattrocento florentino e a historiografia da arte em Aby Warburg" de Serzenando Alves Vieira Neto (2018: 21). Neste último artigo, publicado em língua inglesa, 0 autor defende a perspectiva de que "Warburg se colocou nitidamente alinhado à tradição de "história da arte como história da cultura", presente na obra de autores como Jacob Burckhardt, Anton Springer e Hubert Janitschek". 0 Boletim do Museu Paraense Emílio Goeldi publicou em 2014 "A vida póstuma de Aby Warburg: por que seu pensamento seduz os pesquisadores contemporâneos da imagem?", de Mauricio Lissovsky, no qual se coloca a questão da ressurgência de Warburg:

\footnotetext{
Por que Aby Warburg (1866-1929), cuja fama sempre superou o conhecimento de sua obra, está de volta? Por que alguns dos mais importantes pensadores da estética na atualidade - como o historiador da arte Georges Didi-Huberman e o filósofo Giorgio Agamben - encontram neste obscuro historiador da arte alemão um precursor de seus próprios trabalhos? A voga atual tem uma intensidade inédita, mas está longe de ser a primeira. A 'redescoberta' corrente foi precedida de várias ressurgências anteriores, de menor impacto, como se o próprio Warburg estivesse destinado a ser uma destas imagens 'sobreviventes', que atravessam as eras, e pelas quais tanto se interessou (Lissovsky, 2014: 306).
}

A questão posta por Lissovsky impulsionou muito do que se leu sobre Warburg na última década. Outras revistas brasileiras se juntaram na divulgação do autor em campos diversos, tendo a discussão sobre a imagem como ponto comum. Desde textos didáticos como o do antropólogo Luis Eugenio Campos, que promete um "guía para leer a Aby Warburg" (2014), passando pelo "Aby Warburg em português" de Lenin Bicudo (2016), até o artigo publicado pela Poiesis, em 2011, "As 'Mnemosyne(s) de Aby Warbug: entre Antropologia, Imagens e Arte" de Etienne Samain, convidando historiadores da arte a reorientar-se: "Com Mnemosyne (...) a história da arte tradicional transfigurava-se em uma antropologia do visual" (2011: 36)3. Recentemente, a mesma publicação da Universidade Federal Fluminense publicou "El dinero, una bomba molotov: supervivencias warburguianas en el arte latinoamericano post 68" (Torres; Correa, 2019). ARS (USP) ofereceu à comunidade acadêmica "Uma ninfa a perseguir cabeças: imagens de Salomé na coluna Garotas do Alceu" de Daniela Campos (2016), outra autora também presente nesta edição da MODOS. Campos aparecerá em outras publicações, como Porto Arte (2017) e Revista Brasileira de Estudos da Presença, ao lado de Maria Bernardete Ramos Flores (2018). Já a Revista Educação, Artes e 
Inclusão publicou "A sublevação de Atlas: notas sobre o método de Georges Didi-Huberman" de Luana Wedekin (2019), que também contribuiu nesta edição da MODOS.

Não menos importantes serão os artigos que tomam a fortuna de Warburg como orientação teórica. Larissa Mata (2015) publicou na Revista do Instituto de Estudos Brasileiros, o artigo "Mimetismo e metamorfose". Dois anos antes, a Revista Palíndromo veicula "O 310 Panorama da Arte Brasileira como montagem em Warburg", de Karoline Marianne Barreto (2013). A revista da Udesc também publicou "A recepção italiana de Aby Warbug entre filologia e historiografia da arte", uma entrevista com a filóloga Monica Cestanni, realizada por Thays Tonin (2019). Ao comentar a criação da revista Engramma, dedicada aos estudos de matriz warbuguiana, Cestanni assinala:

\begin{abstract}
Há de se dizer também, no campo da história da arte e a partir da década de 1990, que a redescoberta da iconologia coincidiu com a moda de um "warburguismo genérico" (ainda em voga) que tratou Warburg como um precursor brilhante da antropologia cultural: não por acaso, os referimentos a Warburg terminavam sempre por recair sobre o "Ritual da Serpente" [1923] - o texto mais conhecido de Warburg, traduzido em quase todas as línguas do mundo, mas que na realidade é o texto de uma conferência reunido em circunstâncias muito particulares, completamente excêntricas - em termos de conteúdo e rigor com relação a seus outros escritos, que 0 próprio Warburg tinha absolutamente advertido contra a publicação (apud Tonin, 2019: 168).
\end{abstract}

A lista de artigos mais recentes é novamente grande. Elencamos algumas publicações: Pós (EBA/UFMG) com o texto de Tatiana Martins (2017); Revista de História da Arte e da Cultura com artigo de Priscyla Abreu (2020); Galáxia com a publicação dos trabalhos de Gabriel Malinowski (2018), Francisco Trento (2017), Maria Jacobini (2016); ARS (USP) com os artigos de Cristian Borges e Samuel Jesus (2010) e Luis Pérez-Oramas (2017); Horizonte. Revista de Estudos de Teologia e Ciências da Religião com o texto de Maria Cláudia Magnani (2019); Sequência com o artigo de Francisco Oliveira e Nancy Oliveira (2019);

Os organizadores de nosso dossiê "O retorno a Aby Warburg no discurso historiográfico artístico contemporâneo", Vera Pugliese e Roberto Casazza, participaram ativamente dessa história. Archai publicou, em 2016, "Jonhann J. Winckelmann e Aby Warburg: diferentes olhares sobre os antigos e seus tempos" de Pugliese, que nos lembra que:

Winckelmann inaugurou um modelo que se pretendia objetivo e cujas premissas teórico-metodológicas permitiram olhar para a antiguidade clássica, valorizando a arte grega em detrimento da romana. Mas Aby Warburg escaparia a este grande desenho do mainstream da história da arte, lançando outro olhar sobre o antigo, sob uma proposta teórico-metodológica de diferente natureza (2016: 172).

Este desejo de desviar-se do mainstream foi discutido no artigo "A fórmula de pathos de Wargurg nos contextos psicanalítico e benjaminiano", de Adi Efal, traduzido por Pugliese e publicado na Arte \& Ensaios (EBA/UFRJ), em 2018. Nesta edição da MODOS, a pesquisadora da Universidade de Brasília oferece aos leitores, além da organização do dossiê ao lado de Casazza, três novas traduções de textos inéditos: "Reinventar a primavera, ou as filiações da revolta" de Georges DidiHuberman; "Mnemosyne, ou a cinematografia sem aparelho" de Philippe-Alain Michaud e "Manet, Manebit! O "Manet e a Antiguidade italiana" de Aby Warburg como autorretrato psico-intelectual" de Uwe Fleckner em parceria com Victor Zaiden.

É preciso lembrar que, recentemente, Arthur Valle traduziu para $19 \& 20$ o texto de Joschke Christian "Para que serve a iconografia política?", em que o autor conclui que "a iconografia política responde, portanto, a várias expectativas da história da arte e do público. Ela consegue renovar os quadros da 
iconologia tradicional, cruzando seus métodos e se apoiando naqueles de Warburg; ela dialoga com a história das media e da história política, a ponto de modificar profundamente os reflexos de análise histórica" (Christian, 2020). Recordemos a tradução de Patricia Franca-Huchet do texto de DidiHuberman (2015) para Pós (EBA/UFMG), que tomou uma obra de Pascal Convert à luz do funcionamento da imagem segundo Benjamin e Warburg. Também merece destaque a tradução de Isabel Fragelli de "Epitáfio a Aby Warburg" de Ernst Cassirer (2016), pela Discurso. O mesmo autor terá o texto "O lugar de Kepler na história intelectual europeia" traduzido por Serzenando Vieira Neto para Cadernos de Filosofia Alemã: Crítica e Modernidade.

MODOS também já havia acolhido textos sobre o pensamento warburguiano, como "Polaridades e anacronismos no pensamento de Warburg", de Jorge Coli (2017) e "Virada icônica: um apelo por três voltas no parafuso", de Emmanuel Alloa (2019). Diferentes artigos tomaram Warburg como ponto de reflexão teórico, tais como "A expografia de Lina Bo Bardi como mesa de montagem: transparências, opacidades e genealogias" de Vera Pugliese (2017); "Um projeto mais amplo de cidade: a memória de Lina Bo Bardi por Renata Lucas" de Luciana Valio (2018); "Os arquivos da arte na pathosformeln das redes e nas ruínas do coletivo" de Mauricius Farina (2017); "Da grade múltipla da montagem: perspectivas para a imagem crítica na contemporânea" de Luiz Cláudio da Costa (2017); "Tempo andante da intervenção urbana: relações temporais nas obras Imagens Posteriores, Giganto e Polaroides (in)visiveis" de Ana Rita Vidica (2018); "A montagem de ontem ou relembrando disposições" de Patricia Franca-Huchet (2018); "Modos de conectar em redes instáveis" de Débora Gasparetto (2018); "Não há neutralidade: montagem filmica e exposição para escritas de histórias da arte" de Igor Simões (2018); "Na caverna de Tarsila: sobrevivências do primitivo como presença do não colonial" de Maria Bernardete Ramos Flores e Michele Petry (2019) e "Da "representação das sobras" à "reantropofagia": povos indígenas e arte contemporânea no Brasil" de llana Goldstein (2019).

Assim, MODOS contribui nesse esforço coletivo de difundir os estudos sobre o pensamento de Warbug. Georges Didi-Huberman e Philipe Michaud são dois autores que ajudaram na disseminação do pensamento warburgiano no Brasil e nos brindam com textos inéditos nesta edição. Certamente algumas ausências se farão notar, em especial a de José Emilio Burucúa, cujo livro Historia, Arte, Cultura. De Aby Warburg a Carlo Ginzbug (2003) ampliou o debate sobre 0 historiador alemão em nosso continente. Burucúa é certamente um de seus grandes intérpretes contemporâneos, além de ampliar suas reflexões para outros nomes do círculo warbuguiano (Panofsky, Saxl, Cassier, Klibansky e mesmo Benjamin). Mas, não se trata aqui de uma convenção sobre Warburg e, mesmo que o fosse, a completude nunca se configura.

É evidente que a lista oferecida neste editorial é incompleta. 0 "atlas" de textos e imagens suscitados por Warburg, no Brasil, é muito mais amplo do que conseguimos alcançar. Uma lista de teses, dissertações e livros pode ser consultada no artigo de Fernandes, mencionado acima (2019b).

O que procuramos destacar é a significativa acolhida do aporte warbuguiano entre nós, seja na adoção de seu método, na discussão de suas proposições e na interpretação de suas ideias por outros pensadores e autores, dando a dimensão da força de uma sobrevivência teórica que merece reflexão. Nesse sentido, buscamos testemunhar alguns estudos que fazem juz a esse legado.

Além dos textos do dossiê, MODOS publica artigo de Stefanie Gil Franco, que discute como a noção de art brut em Portugal conformou-se às qualidades específicas do sujeito louco e artista, tendo em Jaime Fernandes um caso pontual para refletir sobre as políticas psiquiátricas e artísticas, especialmente sobre a produção de certos cânones da arte. Em outro artigo, Fernanda de Albuquerque discute a relação entre a produção artística e suas tensões com as instituições 
museológicas contemporâneas, tomando como exemplo o comissionamento de uma obra de Rubens Mano pela Pinacoteca de São Paulo. Já a diplomacia cultural, mais especificamente a exposição Art from Argentina 1920-1994 no Museu de Arte Moderna de Oxford e a inauguração do monumento escultórico do general José de San Martín em Londres, é o objeto do texto de Agustin Diez Fischer. Todos expõem a diversidade de tempos e geografias culturais, visões de artistas e agenciamentos que trazem relevantes reflexões sobre modos de ver, exibir e compreender arte.

E se os monumentos da Antiguidade e do Renascimento, nos quais Warburg se debruçou, parecem tão distantes no tempo e deslocados das pautas dos debates culturais recentes para além dos centros europeus, eles ainda se presentificam em fantasmagorias na contemporaneidade e em outras ações para além da história da arte. Monumentos escultóricos ocuparam notíciários e redes em 2020 graças a movimentos como Black Lives Matter. Movimentos antirracistas há décadas investem no debate sobre a deposição de monumentos em homenagem a exploradores e expropriadores, geralmente atrelados à história da escravidão, a projetos e governos autoritários, a crimes contra humanidade. 0 momento que nos toma reitera o compromisso da arte em prol desse debate, como se faz visível na obra ..love... (when they grow up...), da artista jamaicana Ebony G. Patterson, escolhida para compor nossa última capa de 2020. Suas tapeçarias, aparentemente tão harmoniosas, apresentam comunidades negras atingidas pela violência, pelo tráfico de drogas, pela opressão policial e, sobretudo, destacam a cultura negra jovem global. Engajada em expressar e olhar para o Outro, a artista nos lembra que seu trabalho evoca a tensão entre a inocência e a culpa: "Muitas dessas imagens são inspiradas por essa ideia do que significa testemunhar, o que significa testemunhar e quem tem permissão para participar do ato de testemunhar" (apud Binlot, 2018, online). Ela, assim, constrói seu próprio atlas menmosyne, não com imagens ladeadas que estabelecem diálogos, mas com diversas camadas de vivências e memórias que se superpõem, mesclam-se e se transforam em sua poética, gerando confrontos e encantamentos. Sua ninfa negra não usa veste esvoaçante, mas como figura central e com perfil marcante, é testemunha altiva do legado do passado e da permanência dos preconceitos raciais e de gênero. Entre duas figuras masculinas passivas, ela se mantém fortalecida na sua sobrevivência, ciente da sua descendência dos mitos de origem matriarcal africanos, com bordados e apliques, coisas do feminino, que transbordam uma imagem resignada.

Como apontou Ebony G. Patterson, todos somos testemunhas tanto do que escolhemos testemunhar do mundo que nos cerca, quanto dos atos artísticos que nos trazem outros modos de ver o passado e o presente do mundo. Produzir, pensar e divulgar arte é um ato político e é nesse sentido que precisamos permanecer alertas e ativos para que cada vez mais pessoas tenham acesso à participação do ato de testemunhar arte e com ela se enformar.

Ilhados em nossas casas por uma pandemia global, como meio de sobrevivência ficamos ligados às redes sociais, a espetáculos, exposições, eventos, lives e aulas online, inventando outros meios de experienciar a arte. Na loucura, nos protestos, nas subversões, mas também no isolamento como ato cidadão, a arte e a história da arte assumem posições libertárias, no sentido de estarem sempre testemunhando o que de humano temos em nós e quanto de Mnemosyne nos sustenta em momentos cujo atlas se mostra cada vez mais desigual e estilhaçado em pedaços desconexos.

Para concluirmos, gostaríamos de agradecer nesta edição à Vera Pugliese e a Roberto Casazza pela organização do dossiê, às autoras e aos autores pelos textos submetidos; aos tradutores pelo empenho em trazer para língua portuguesa textos inéditos em francês e alemão, ampliando assim a difusão de seus conteúdos para o mundo lusófono. E reforçamos nossa gratidão aos pareceristas que ponderam a qualidade dos artigos publicados, ao designer que sustenta nossa identidade visual e a todos que colaboraram para que, com a última edição de 2020, concluamos o quarto ano de 
vida da revista MODOS. Um especial agradecimento aos nossos leitores que têm permitido qualificar a revista MODOS como um dos mais importantes periódicos em artes do país. Mesmo impedidos das sociabilidades necessárias à condição humana e à arte, continuamos a querer testemunhar a resistência. Vamos em frente.

\section{Referências}

ABREU, P. K. V. Desenhos de figurinos de Alexandra Exter para Aelita, rainha de Marte. Revista De História da Arte e da Cultura, 1(1), 81-104. Disponível em: <https://doi.org/10.20396/rhac.v111.13681>.

ALLOA, E. Virada icônica: um apelo por três voltas no parafuso. Tradução de Aline Rena. MODOS. Revista de História da Arte. Campinas, v. 3, n.1 , p. 91-113, jan. 2019. Disponível em: <https://doi.org/10.24978/mod.v3i1.4077>.

BARBOZA MARTÍNEZ, A. Sobre el método de la interpretación documental y el uso de las imágenes en la sociología: Karl Mannheim, Aby Warburg y Pierre Bourdieu. Sociedade e Estado, vol. 21, n. 2, p.391-414, ago 2006.

BARRETO, K. M. O $31^{\circ}$ Panorama da Arte Brasileira como montagem em Warburg, Revista Palíndromo, vol.5, n.9. Disponível em: $<$ https://doi.org/10.5965/217523460509201321 $0>$.

BARTHOLOMEU, C. Dossiê Aby Warburg, Arte \& Ensaios, n. 19, 2009, p.118-143.

BICUDO BÁRBARA, L. Aby Warburg em português. Discurso, 46(1),255-270, 2016. Disponivel em:

<https://doi.org/10.11606/issn.2318-

8863.discurso.2016.119164>.

BINLOT, A. "Above, below, beneath" provides a window into the political stakes of Ebony $G$. Patterson's decadent, intricate tapestries from Document's Fall/Winter 2018 issue, Document Journal, n013, nov. 2018. Disponível em: $<$ https://www.documentjournal.com/2018/11/eb ony-g-patterson-flashes-her-discordantopulence/>.

BORGES, C.; JESUS, S. de. Memória de gestos na obra de Agnès Varda: pintura, fotografia, cinema, ARS (São Paulo), vol. 8, n. 16, p. 6572, 2010. Disponível em: $<$ https://doi.org/10.1590/S167853202010000200005>.

BURUCÚA, J. E. Historia, arte, cultura. De Aby Warbug a Carlo Ginzburg.1 edición. Buenos Aires, Fundo de Cultura Económica, 2003.

Repercussões de Aby Warburg na América Latina, Concinnitas, vol. 21, n. 2, dez. 2012, p.252-280. Trad. de Alberto Chillón. Disponível em: <https://www.e- publicacoes.uerj.br/index.php/concinnitas/article /view/12434/9655>.

CAMPOS, D. Q. Uma ninfa à perseguir cabeças: imagens de Salomé na coluna Garotas do Alceu, ARS (USP), vol.14, $\mathrm{n}^{0} 28,2016$. Disponível em:<https://doi.org/10.11606/issn.21780447.ars.2016.118373>.

Uma outra ninfa moderna: A pin-up como uma ninfa de Aby Warburg e Georges DidiHuberman, Porto Arte, vol.22, n³6, 2017. Disponível em: <https://doi.org/10.22456/21798001.56421>.

FLORES, M. B. R. Vênus Desnuda: a nudez entre 0 pudor e o horror. REVISTA BRASILEIRA DE ESTUDOS DA PRESENÇA, $v$. 8, p. 248-276, 2018.

CAMPOS, L. E. Conhecendo Aby Warburg, Trans/Form/Ação, vol. 37, n. 1, p. 151162, abril 2014. Disponível em $<$ https://doi.org/10.1590/S010131732014000100008>.

CASSIRER, E.; VIEIRA NETO, S. O lugar de Kepler na história intelectual europeia. Cadernos De Filosofia Alemã: Crítica $E$ Modernidade, 25(1), 165-174, 2020 Disponível em: $\quad<h t t p s: / / d o i . o r g / 10.11606 / i s s n .2318-$ 9800.v25i1p165-174>.

COLI, J. Polaridades e anacronismos no pensamento de Warburg. MODOS. Revista de História da Arte. Campinas, v. 1, n. 2, p.09-21, mai. 2017. Disponível em: <https://doi.org/10.24978/mod.v1i2.755>.

COSTA, L. C. Da grade múltipla da montagem: perspectivas para a imagem crítica na contemporânea. MODOS. Revista de História da Arte. Campinas, v. 1, n. 2, p. 98-112, mai. $2017 . \quad$ Disponivel em: <https://doi.org/10.24978/mod.v1i2.761>.

DIDI-HUBERMAN, G.; FRANCA-HUCHET, P. Imagem, evento, duração. Pós: Revista do Programa de Pós-graduação em Artes da EBA/UFMG, vol. 2, n. 4, nov.2012. Disponível em: $\quad<$ https://periodicosdes.cecom.ufmg.br/index.php/revistapos/article/ view/15454>

EFAL, A. A "Fórmula de Pathos" de Warburg nos contextos Psicanalítico e Benjaminiano. Arte \& Ensaios, n 35, trad. de Vera Pugliese, p. 196- 
211, 2018,. Disponível em: $<$ https://revistas.ufrj.br/index.php/ae/article/view /15661>

FARINA, M. Os arquivos da arte na pathosformeln das redes e nas ruínas do coletivo. MODOS. Revista de História da Arte. Campinas, v. 1, n.2, p. 113-123, mai. 2017. Disponível em: <https://doi.org/10.24978/mod.v1i2.762>.

FERNANDES, C. Aby Warburg entre a arte florentina em retrato e em retrato de Florença na época de Lorenzo de Medici, História: Questões \& Debates, vol. 41, n. 2, 2004. Disponível em: $<$ https://revistas.ufpr.br/historia/article/view/463 $1>$.

Jacob Burckhardt e Aby Warburg: da arte à civilização italiana do Renascimento, LocusRevista de História, vol. 12, n. 1, p.127-143, 2006.

Aby Warburg: a astrologia como instrumento de orientação do homem no cosmos, Concinnitas, vol. 20, n. 36, 2019a.

Aby Warburg negli studi latino-americani, Engramma. La tradizione classica nella memoria occidentale, v. 165, 2019b. Disponível em: $<$ http://www.engramma.it/eOS/index.php?id_arti colo $=3610>$.

Aby Warburg: intercâmbios culturais entre o Norte e o Sul. Visualidades, vol. 17, n. 26, 2019c. Disponível em: <https://doi.org/10.5216/vis.v17.57277>.

FLORES, M. B. R.; PETRY, M. B. Na caverna de Tarsila: sobrevivências do primitivo como presença do não colonial. MODOS. Revista de História da Arte. Campinas, v. 3, n.1, p. 115-132, jan. 2019. Disponível em: <https://doi.org/10.24978/mod.v3i1.3770>.

FRANCA-HUCHET, P. A montagem de ontem ou relembrando disposições. MODOS. Revista de História da Arte. Campinas, v. 2, n.1, p.260275, jan. 2018. Disponivel em:<https://doi.org/10.24978/mod.v2i1.907>.

GASPARETTO, D.A. Modos de conectar em redes instáveis. MODOS. Revista de História da Arte. Campinas, v. 2, n.2, p.73-90, mai. 2018. Disponível <https://doi.org/10.24978/mod.v2i2.915>.

GOLDSTEIN, I. S. Da "representação das sobras" à "reantropofagia": povos indígenas e arte contemporânea no Brasil. MODOS. Revista de História da Arte. Campinas, v. 3, n. 3, p. 6896, set. 2019. Disponivel em: <https://doi.org/10.24978/mod.v3i3.4304>.

JACOBINI, M. L. De influências e sobrevivências: a transposição de uma memória de imagens por entre movimentos artísticosculturais, Galáxia (São Paulo), n.31, p.196-200, jun 2016.
JOSCHKE, C. Para que serve a iconografia política? 19\&20, Rio de Janeiro, v. XV, n. 1, jan.jun. 2020. Trad. Arthur Valle. Disponivel em:<http://www.dezenovevinte.net/ha/joschke.h tm>.

LEHMKUHL, L. O lugar da imagem na reinstalação warburguiana, ArtCultura, 7 (11), $2005 . \quad$ Disponível em: $<$ http://www.seer.ufu.br/index.php/artcultura/arti cle/view/1354>.

LISSOVSKY, M. A vida póstuma de Aby Warburg: por que seu pensamento seduz os pesquisadores contemporâneos da imagem?. Boletim do Museu Paraense Emílio Goeldi. Ciências Humanas, Belém, v. 9, n. 2, p. 305-322, ug. 2014 . Disponível em: $<$ https://doi.org/10.1590/198181222014000200004>.

MAGNANI, M. C. A. Sibilas: a sobrevivência das profetisas pagãs no mundo cristão, Horizonte. Revista de Estudos de Teologia e Ciências da Religião, vol. 17, n. 54, dez. 2019.

MALINOWSKI, G. Ato, atalho e vento: as fórmulas de páthos na história do cinema, Galáxia (São Paulo), n.37, p.109-119, abr. 2018.

MARTÍNEZ, I. U. El Arte como manipulación en Aby Warburg, Revista de Filosofia: Aurora, vol. 22, n. 31, 2010. Disponivel em: $<$ https://periodicos.pucpr.br/index.php/aurora/ar ticle/view/2542>.

MARTINS, T. O museu como ensaio contemporâneo, Pós: Revista do Programa de Pós-graduação em Artes da EBA/UFMG, vol. 7, n. 13, mai.2017. Disponivel em: $<$ https://periodicos.ufmg.br/index.php/revistapo s/article/view/15704>.

MATA, L. C. da. Mimetismo e metamorfose. Revista do Instituto de Estudos Brasileiros, (61), 103-121, 2015. Disponível em: $<$ https://doi.org/10.11606/issn.2316901X.v0i61p103-121>.

MATTOS, C. V. Arquivos da Memória: Aby Warburg e a História da Arte e a Arte Contemporânea, Concinnitas, vol.11, 2007, p.130-139.

OLIVEIRA, F.C.; OLIVEIRA, N. Leis, Serpentes e Baratas: análise reconstrutiva da sobrevivência das formas de fundamentos do Direito Moderno e seus efeitos na realidade brasileira. Sequência (Florianópolis), n. 81, p. 131-154, abr. 2019. Disponível em: $<$ http://dx.doi.org/10.5007/2177-

7055.2019v40n81p131>.

PÉREZ-ORAMAS, L. Parangolé-Botticelli: pensamento da montagem e razão prática da história da arte. Forma transicional e geometria do carnaval, ARS (São Paulo), ago 2017, vol. 15, n.30, p.233-254. 
PUGLIESE, V. Jonhann J. Winckelmann e Aby Warburg: diferentes olhares sobre os antigos e seus tempi, Archai. Revista sobre as Origens do Pensamento Ocidental, n. 18, p. 171-215, sept.dec 2016. Disponível em: <http://dx.doi.org/10.14195/1984 -249X_18_5>.

A expografia de Lina Bo Bardi como mesa de montagem: transparências, opacidades e genealogias. MODOS. Revista de História da Arte. Campinas, v. 1, n. 2, p. 145-168, mai. 2017. Disponível em: <https://doi.org/10.24978/mod.v1i2.747>.

SAMAIN, E. As 'Mnemosyne(s) de Aby Warbug: Entre Antropologia, Imagens e Artre, Poiesis, n. 17, jul. 2011. Disponível em: <https://doi.org/10.22409/poiesis.1217.29-51>.

Antropologia, imagens e arte. Um percurso reflexivo a partir de Georges DidiHuberman, Cadernos de Arte e Antropologia, vol. 3, n. 2, 2014, Disponíve em: <https://doi.org/10.4000/cadernosaa.391>.

SIMÕES, I. M. Não há neutralidade: montagem fílmica e exposição para escritas de histórias da arte. MODOS. Revista de História da Arte. Campinas, v. 2, n. 3, p. 67-83, set. 2018. Disponível <https://doi.org/10.24978/mod.v2i3.1051>.

TEIXEIRA, F. C. Aby Warburg e a pós-vida das Pathosformeln antigas. História da Historiografia: International Journal of Theory and History of Historiography, v. 3, n. 5, p. 134147, 13 set. 2010.

TRENTO, F. B. Vivendo sob os murmúrios de Atlas. Galáxia (São Paulo), n.35, p.132-139, ago 2017

TONIN, T. "A recepção italiana de Aby Warbug entre filologia e historiogradia da arte",
Palíndromo, v. 11, n. 24, p. 162-179, maio 2019. Disponível

em: $<$ http://dx.doi.org/10.5965/21752346112420191 62>.

TORRES, N.; CORREA, J. El dinero, una bomba molotov: supervivencias warburguianas en el arte latinoamericano post 68 , Poiesis, v. $20, \mathrm{n}$. 34, 2019. Disponível em: <https://doi.org/10.22409/poiesis.v20i34.36385 $>$.

VALIO, L. B. M. Um projeto mais amplo de cidade: a memória de Lina Bo Bardi por Renata Lucas. MODOS. Revista de História da Arte. Campinas, v. 2, n. 2, p.54-71, mai. 2018. Disponível <https://doi.org/10.24978/mod.v2i2.902>

VIDICA, A. R. Tempo andante da intervenção urbana: relações temporais nas obras Imagens Posteriores, Giganto e Polaroides (in)visiveis. MODOS. Revista de História da Arte. Campinas, v. 2, n.1, p.111-131, jan. 2018. Disponível em: <https://doi.org/10.24978/mod.v2i1.900>.

VIEIRA NETO, S. A. O Quattrocento florentino e a historiografia da arte em Aby Warburg, História da Historiografia: International Journal of Theory and History of Historiography, v. 11, n. 28, 8 dez. 2018.

WEDEKIN, L. A sublevação de Atlas: notas sobre o método de Georges Didi-Huberman, Revista Educação, Artes e Inclusão, vol.15, n. 1, 2019

WARBURG, A. O problema está no meio. In: A renovação da Antiguidade pagã: contribuições científico-culturais para a história do Renascimento europeu. Rio de Janeiro: Contraponto, 2013.

\footnotetext{
${ }^{1}$ Mnemosyne de Aby Warbubg foi traduzido por Barbara Szaniecki e contou com a revisão técnica de Inês de Araujo. Já o texto de Agamben foi traduzido por Richard Andeol, com revisões de Ângela Lopes e Guilherme Delgado (Bartholomeu, 2009).

2 Fernandes escreve um texto fundamental para o assunto, "Aby Warburg negli studi latino-americani", publicado na Revista Engramma (2019b), em que compila as referências bibliográficas que difundiram o pensamento de Warburg na América Latina. 3 Samain (2014) publicou posteriormente "Antropologia, imagens e arte. Um percurso reflexivo a partir de Geogers Didi-Huberman", no qual retoma as fronteiras entre a história da arte e antropologia e a leitura de Didi-Huberman sobre Benjamin e Warburg.
} 